Provided for non-commercial research and education use. Not for reproduction, distribution or commercial use.

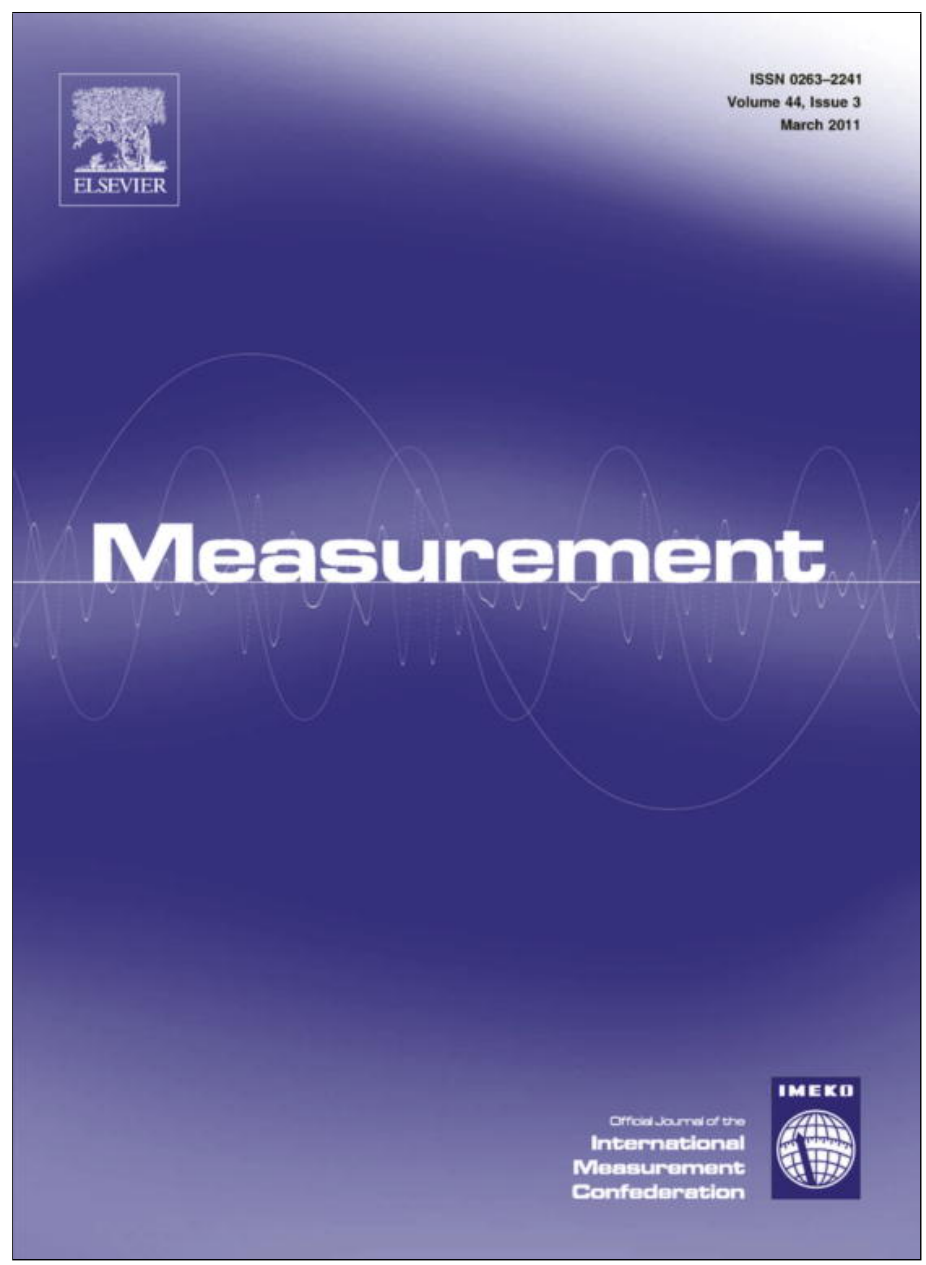

This article appeared in a journal published by Elsevier. The attached copy is furnished to the author for internal non-commercial research and education use, including for instruction at the authors institution and sharing with colleagues.

Other uses, including reproduction and distribution, or selling or licensing copies, or posting to personal, institutional or third party websites are prohibited.

In most cases authors are permitted to post their version of the article (e.g. in Word or Tex form) to their personal website or institutional repository. Authors requiring further information regarding Elsevier's archiving and manuscript policies are encouraged to visit:

http://www.elsevier.com/copyright 


\title{
Thin bonding wires temperature measurement using optical fiber sensors
}

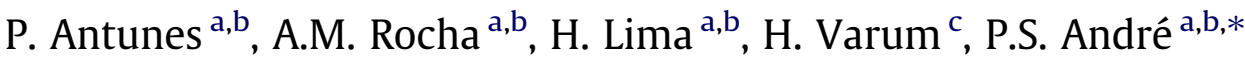 \\ a Instituto de Telecomunicações, Campus Universitário de Santiago, 3810-193 Aveiro, Portugal \\ ${ }^{\mathrm{b}}$ Departamento de Física da Universidade de Aveiro, Campus Universitário de Santiago, 3810-193 Aveiro, Portugal \\ ${ }^{\mathrm{c}}$ Departamento de Engenharia Civil da Universidade de Aveiro, Campus Universitário de Santiago, 3810-193 Aveiro, Portugal
}

\section{A R T I C L E I N F O}

\section{Article history:}

Received 6 May 2010

Received in revised form 8 November 2010

Accepted 18 November 2010

Available online 6 December 2010

\section{Keywords:}

FBG

Bonding wire

Optical fibers

\begin{abstract}
A B S T R A C T
In this work we demonstrate the use of optical fiber sensors to measure temperature in thin metallic bonding wires. Temperature was measured in copper wires with diameter of 0.10 , $0.28,0.60$ and $0.70 \mathrm{~mm}$ and for different values of the driven electrical current (0.75$10.00 \mathrm{~A}$ ). A theoretical model for the system, which takes into account the relevant heat exchange mechanism, was developed. The results demonstrate the feasibility of the optical sensors application for the measurement of temperature in thin metallic bonding wires.
\end{abstract}

(C) 2010 Elsevier Ltd. All rights reserved.

\section{Introduction}

Thin metallic wires are widely used in electronic and optoelectronic components and devices. Nevertheless, their reduced cross section can cause them to fuse at low electrical currents, driving to the permanent equipment failure. Therefore, it is useful to be able to monitor the temperature evolution of thin bonding wires and to develop methods to predict its maximum achieved temperature as a function of the driving electrical current.

In the last few decades, electronic devices have become more powerful within ever decreasing package sizes. This implies thinner bond wires, conducting higher currents, with an increase in their operating temperatures. Wire temperature values can be measured using infrared thermal CCDs [16,4], however the image pixel resolution is usually greater than that of the dimensions of the wire, leading to errors in calculating the real temperature. Several methods have been proposed to compute and estimate the maximum current that can be conducted in a thin bonding wire [12-14].

\footnotetext{
* Corresponding author at: Instituto de Telecomunicações, Campus Universitário de Santiago, 3810-193 Aveiro, Portugal. Tel.: +351 234 377900; fax: +351234377901.

E-mail address: pandre@av.it.pt (P.S. André).
}

The method here proposed, can be used to determine experimentally, in a nonintrusive way, and in real time the temperature of the metallic wire. By this way, the maximum allowed current can be estimated for each specific situation, improving the device efficiency without causing damage.

Optical fiber sensors based in-fiber Bragg gratings (FBG) had been used to measure static [11] and dynamic [3] parameters, including temperature. Since FBG are in-fiber sensors they have inherent advantages, such as small weight, immunity to electromagnetic interference and the possibility of multiplexing a large number of sensors and low noise.

The big challenge to overcome in monitoring thin wires temperature is the dimension (diameter) of the optical fiber, which are typically greater than the dimension of the wire being monitored. Therefore, the sensor heat capacity cannot be neglected when calculating the wire temperature. Therefore, an accurate thermal model for the system is necessary in order to correctly predict the real wire temperature values.

In this work, we have developed a method to predict thin wires temperature, based on data acquired by an FBG optical sensor placed in contact with the wire. Moreover, we developed a theoretical model that allows us to predict the real temperature of the thin wires as function of the electrical current conducted. 
This paper is organized as follows: following the introduction a description of the implementation of an FBG as temperature sensor is given. The theoretical temperature model is presented in the subsequent section as are the experimental and simulation results. The last section presents the conclusions of the work.

\section{FBG for temperature monitoring}

An FBG is recorded by imposing a periodical refractive index modulation, along the longitudinal axis of the core of a photosensitive optical fiber. The index modulation is induced by exposing a photosensitive optical fiber to an ultraviolet (UV) radiation periodic pattern, created by a phase mask or by interferometric processes. When this periodic structure is illuminated by a broad spectral band signal, it selectively reflects a narrow spectral band. The centre wavelength of the reflected signal is referred as the Bragg wavelength, $\lambda_{\mathrm{B}}$, since satisfies the first order Bragg condition, as follows:

$\lambda_{B}=2 n_{e f} \Lambda$

where $n_{e f}$ is the effective refractive index of the optical fiber and $\Lambda$ is the pitch of the refractive index modulation. The Bragg wavelength is affected by the external temperature and strain experienced by the fiber [15]. This dependence of $\lambda_{\mathrm{B}}$ can be described by:

$\Delta \lambda_{B}=2\left(\Lambda \frac{\partial n_{\text {eff }}}{\partial l}+n_{\text {eff }} \frac{\partial \Lambda}{\partial l}\right) \Delta l+2\left(\Lambda \frac{\partial n_{\text {eff }}}{\partial T}+n_{\text {eff }} \frac{\partial \Lambda}{\partial T}\right) \Delta T$

The first term in Eq. (2) represents the strain effect on the Bragg wavelength. The second term in Eq. (2) corresponds to the temperature dependence, which can be expressed as:

$\Delta \lambda_{B}=\lambda_{B}\left[\alpha_{\Lambda}+\alpha_{n}\right] \Delta T$

where $\alpha_{\Lambda}$ is the thermal expansion coefficient and $\alpha_{n}$ the thermo-optic coefficient. For a typical Germanosilicate core doped optical fiber at $1550 \mathrm{~nm}$, the thermal sensitivity is $13 \mathrm{pm} \mathrm{K}^{-1}$ [15].

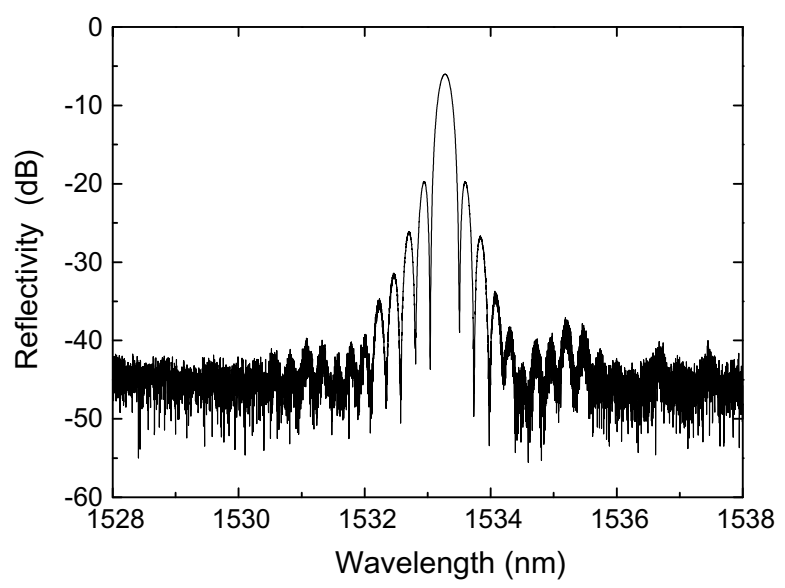

The FBGs temperature and strain response is encoded in the wavelength domain, which is an advantage in terms of signal to noise ratio, but places several constrains on the methods for interrogation. Several techniques based on simple interferometry [9], Fabry-Perot filters [10], matched gratings [6], acoustic-optic tunable filters [18], tunable lasers, long period gratings $[19,8]$, Sagnac loops based on the chirped fiber Bragg gratings [20] or multiport fiber Mach-Zehnder interferometer for multi sensors interrogation [7] can be used to collect data from FBGs [3].

The FBGs used in this work were recorded in photosensitive single mode fiber (FiberCore PS1250/1500) with a $248 \mathrm{~nm} \mathrm{KrF}$ laser, using the phase mask technique and with a length of $3 \mathrm{~mm}$. In order to characterize the grating temperature sensitivity, the fiber (with the FBG superimposed) was placed over a thermoelectric module and covered with heat sink compound to smooth the progress of heat transfer. The thermoelectric module is controlled by a ThorLabs controller model TED 350 using a LM335 as temperature sensor. The FBG Bragg wavelength is collected by an interrogation unit from Micron Optics, model SM125. Fig. 1a displays the reflection spectrum for the FBG used in this work at $20{ }^{\circ} \mathrm{C}$ and Fig. $1 \mathrm{~b}$ shows the data for the Bragg wavelength as function of the grating temperature. The latter data is well modeled assuming a linear dependence, yielding to a thermal sensitivity of $8.93 \pm 0.08 \mathrm{pm}^{\circ} \mathrm{C}^{-1}$, Fig $1 \mathrm{~b}$.

\section{Theoretical thermal model}

The system under analysis is composed of a thin copper wire and of an optical fiber placed alongside with the thin wire. To promote the thermal contact between the wire and the sensor high thermal conductivity heat sink compound is used, smoothing the progress of heat transfer from the wire to the optical fiber.

The three thermal mechanisms by which a device exchanges heat energy with the surroundings are the conduction, convection and radiation. In the development of the thermal model we have considered that the device temperature is closer to the environmental temperature value, and consequently the losses by radiation can be neglected.

In order to model the thermal response of the system we consider the thermal equivalent circuit shown in

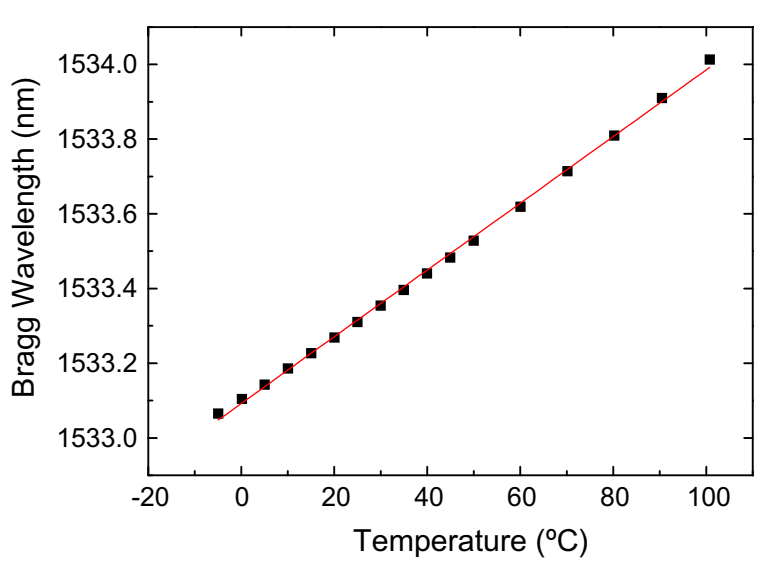

Fig. 1. (a) Fiber Bragg grating reflection spectrum. (b) Thermal characterization showing the Bragg wavelength as function of the grating temperature. The solid line corresponds to the data best linear fit (correlation factor $>0.999$ ). 


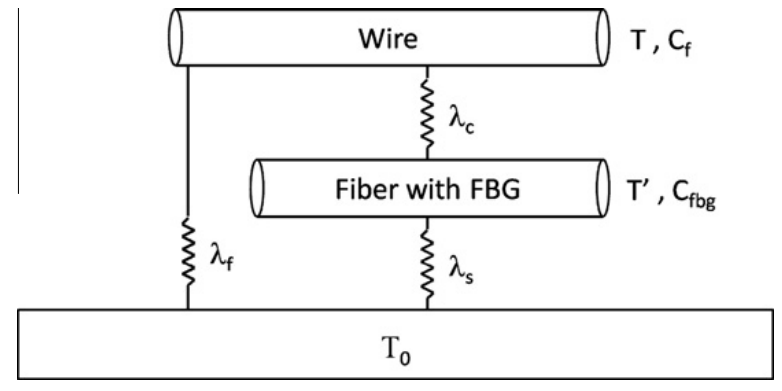

Fig. 2. Schematic representation of the equivalent thermal circuit.

Fig. 2. Given that the heat capacity of the sensor is not negligible, when compared with that of the wire, the measured temperature value $\left(T^{\prime}\right)$ is different than the real wire temperature $(T)[1]$.

This system is governed by the following set of balance equations:

$$
\left\{\begin{array}{l}
P_{\text {ele }}=C_{f} \frac{d T}{d t}+\lambda_{c}\left(T-T^{\prime}\right)+\lambda_{s}\left(T-T_{0}\right) \\
0=C_{f b g} \frac{d T^{\prime}}{d t}+\lambda_{c}\left(T^{\prime}-T\right)+\lambda_{f}\left(T^{\prime}-T_{0}\right)
\end{array}\right.
$$

where $C_{f}$ and $C_{f b g}$ are the wire and optical fiber heat capacity, respectively, $P_{\text {ele }}$ is the thermal power dissipated in the wire due to the electrical current, $T_{0}$ is the environment temperature, $\lambda_{c}$ represents the thermal conductance between the wire and the optical fiber, $\lambda_{s}$ the thermal conductance between the optical fiber and the surrounding and $\lambda_{f}$ the thermal conductance between the wire and the surrounding.

The supplied thermal power is originating from the Joule effect caused by the passage of current by the bonding wires. This hest is a function of the electrical resistance, which is temperature dependent. From the general Ohm law, considering the thermal dependence of the electric resistivity:

$P_{\text {ele }}=I^{2} \frac{l}{\sigma_{0} A_{w}}\left[1+\alpha\left(T-T_{0}\right)\right]$

where $I$ is the electrical current, $\sigma_{0}$ the electrical conductivity, $l$ the wire length, $A_{w}$ the wire area $\alpha$ the resistance thermal coefficient, $T_{0}$ is a reference temperature (usually room temperature) and $R_{0}$ is the resistance at $T_{0}$.

Replacing $T$ in the system of Eq. (4), the following nonhomogeneous second order linear differential equation should be considered:

$a \frac{d^{2} T^{\prime}}{d t^{2}}+b \frac{d T^{\prime}}{d t}+c T^{\prime}=d$

where the second order, first order, linear and independent terms, defined as $a, b, c$ and $d$, respectively, are given by:

$$
\begin{aligned}
& a=C_{f} \frac{C_{f b g}}{\lambda_{c}} \\
& b=C_{f}\left(1+\frac{\lambda_{f}}{\lambda_{c}}\right)+\frac{C_{f b g}}{\lambda_{c}}\left(\lambda_{c}+\lambda_{s}-\frac{l \alpha l^{2}}{\sigma_{0} A_{w}}\right) \\
& c=\lambda_{s}+\lambda_{f}-\frac{\lambda_{s} \lambda_{f}}{\lambda_{c}}-\frac{l \alpha l^{2}}{\sigma_{0} A_{w}}\left(1+\frac{\lambda_{f}}{\lambda_{c}}\right) \\
& d=\frac{l l^{2}}{\sigma_{0} A_{w}}+c T_{0}
\end{aligned}
$$

The second order differential Eq. (6) has as solution:
$T^{\prime}=\frac{d}{c}+A_{1} \exp \left(r_{1} t\right)+A_{2} \exp \left(r_{2} t\right)$

being

$r_{1}=\frac{-b-\sqrt{b^{2}-4 a c}}{2 a} ; \quad r_{2}=\frac{-b+\sqrt{b^{2}-4 a c}}{2 a}$

$A_{1}=\frac{(d / c)-T_{0}}{\left(r_{1} / r_{2}\right)-1} ; \quad A_{2}=\frac{T_{0}-(d / c)}{1-\left(r_{2} / r 1\right)}$

For the cooling cycles (after turning off the electrical current) the term $T_{0}$ in Eq. (10) represents the temperature value at the instant where the current is switch off and $I$ in Eq. (7) is set to zero. For heating cycles the term $T_{0}$ is the environmental temperature. The real temperature value in the wire could be obtained from the temperature measured at the fiber, solving Eq. (4) in order to obtain $T$ :

$T=\frac{C_{f b g}}{\lambda_{c}} \frac{d T^{\prime}}{d t}+\frac{\lambda_{f}}{\lambda_{c}}\left(T^{\prime}-T_{0}\right)+T^{\prime}$

\section{Experimental implementation}

In order to demonstrate the proposed technique, we implemented an experimental system with four copper wires, with diameters of $0.10,0.28,0.60$ and $0.70 \mathrm{~mm}$. For each wire four different electrical current values were applied and the temperature measured with an optical FBG sensor.

Fig. 3 shows a diagram of the implemented setup. The voltage power source controls the injected current. The amperimeter (A) and voltimeter (V), from UniVolt (model DT-6002), allows the measurement of the current and applied voltage, allowing the estimation of the dissipated power.

Data from the optical sensor was collected by an optical interrogation unit from FiberSensing, model FS4200, at five samples per second and the electrical current injected in the wires controlled by a voltage power source from FOC Inc. $\left(I_{\max }=10 \mathrm{~A}, V_{\max }=5 \mathrm{~V}\right)$ allowing to set the current values from 0 to $10 \mathrm{~A}$. The optical fiber (containing the FBG sensor) was placed alongside the wire and a high thermal conductivity heat sink compound was applied between them, to improve the progress of heat transfer from the wire to the optical fiber. The electrical current was applied during $200 \mathrm{~s}$ and then the current was switched off. The temperature values, collected for each

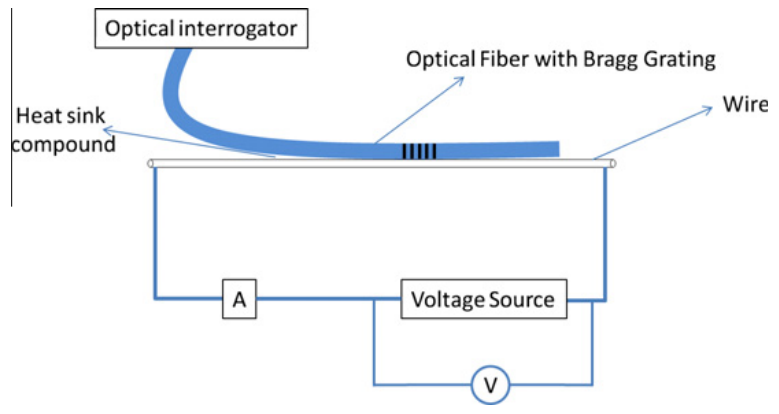

Fig. 3. Representation of the implemented setup. 

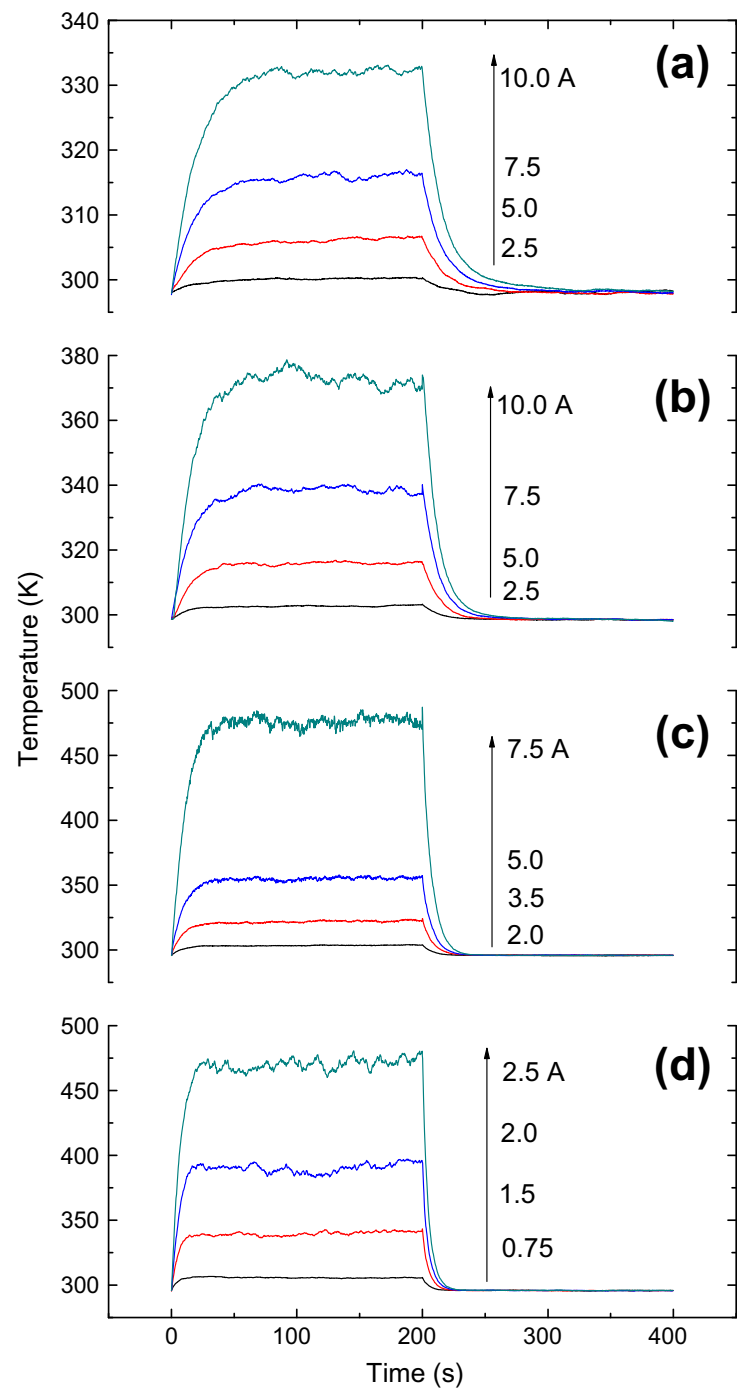

Fig. 4. Temperature data measured with the FBG-based sensor as function of time for different electrical currents and for several wires diameters: (a) $0.70 \mathrm{~mm}$, (b) $0.60 \mathrm{~mm}$, (c) $0.28 \mathrm{~mm}$ and (d) $0.10 \mathrm{~mm}$.

wire and for several values of the electrical current, are presented in Fig. 4.

\section{Results and discussion}

The time dependence of the temperature values was fitted using expression (8). A Nelder-Mead simplex (direct
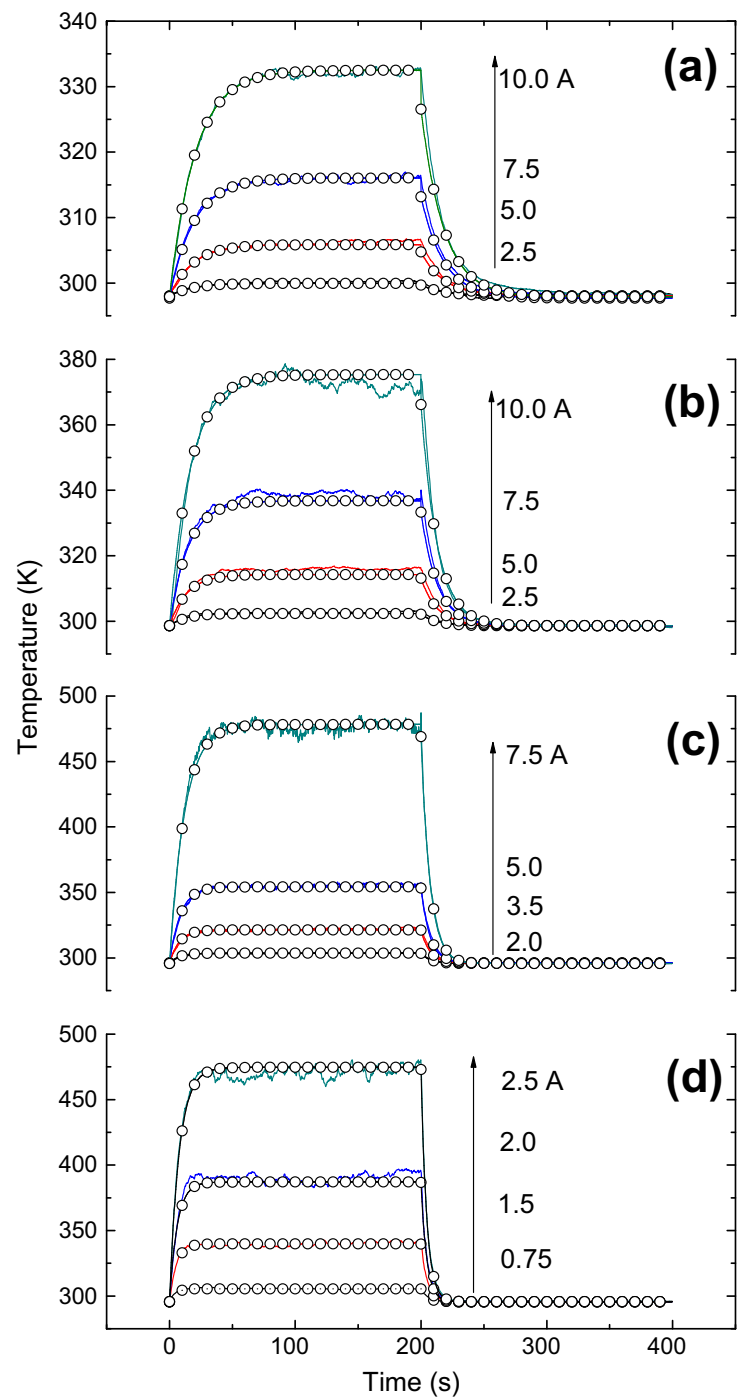

Fig. 5. Temperature measured on the wires with diameter values of: (a) $0.70 \mathrm{~mm}$, (b) $0.60 \mathrm{~mm}$, (c) $0.28 \mathrm{~mm}$ and (d) $0.10 \mathrm{~mm}$. The solid line corresponds to the simulated curves, using the thermal parameters obtained through the minimization process.

search) method was used to minimize the sum of square errors between the measured values and those numerically obtained.

The optimization function was implemented in order to minimize simultaneously the 16 sets of experimental data, four electrical currents for the four thin wires.

Table 1

Initial and final estimated Thermal Parameters Values.

\begin{tabular}{|c|c|c|c|c|c|}
\hline \multirow[t]{2}{*}{ Parameter } & \multicolumn{5}{|l|}{ Wire } \\
\hline & & $0.10 \mathrm{~mm}$ & $0.28 \mathrm{~mm}$ & $0.60 \mathrm{~mm}$ & $0.70 \mathrm{~mm}$ \\
\hline \multirow[t]{2}{*}{$C_{f}\left(\mathrm{~J} \mathrm{~kg}^{-1} \mathrm{~K}^{-1}\right)$} & Initial value & $5.91 \times 10^{-3}$ & $4.63 \times 10^{-2}$ & 0.213 & 0.289 \\
\hline & Final value & $5.71 \times 10^{-2}$ & $1.53 \times 10^{-1}$ & 0.216 & 0.492 \\
\hline \multirow[t]{2}{*}{$C_{f b g}\left(\mathrm{~J} \mathrm{~kg}^{-1} \mathrm{~K}^{-1}\right)$} & Initial value & $1.02 \times 10^{-3}$ & & & \\
\hline & Final value & $6.75 \times 10^{-2}$ & & & \\
\hline \multirow[t]{2}{*}{$\lambda_{c}\left(\mathrm{~K}^{-1}\right)$} & Initial value & 22.22 & 34.57 & 41.38 & 42.42 \\
\hline & Final value & 133.92 & 109.15 & 1383.45 & 181.09 \\
\hline \multirow[t]{2}{*}{$\lambda_{f}\left(\mathrm{~K}^{-1}\right)$} & Initial value & $1.35 \times 10^{-2}$ & $1.35 \times 10^{-2}$ & $1.35 \times 10^{-2}$ & $1.35 \times 10^{-2}$ \\
\hline & Final value & $1.86 \times 10^{-2}$ & $2.76 \times 10^{-2}$ & $1.60 \times 10^{-2}$ & $3.45 \times 10^{-3}$ \\
\hline \multirow[t]{2}{*}{$\lambda_{s}\left(\mathrm{~K}^{-1}\right)$} & Initial value & $3.42 \times 10^{-3}$ & $9.59 \times 10^{-3}$ & $2.05 \times 10^{-2}$ & $2.40 \times 10^{-2}$ \\
\hline & Final value & $9.13 \times 10^{-3}$ & $3.87 \times 10^{-3}$ & $5.96 \times 10^{-3}$ & $2.78 \times 10^{-2}$ \\
\hline
\end{tabular}


The initial values for the minimization were chosen from a set of physical reasonable values collected from literature $[17,2,5]$, Table 1 . The variable $C_{f b g}$ was imposed to be constant for all the wires.

The $\lambda_{c}$ initial value was estimated from an approximation of the contact area between the wire and the optical fiber, considering also the thermal conductivity of the heat sink compound $\left(2 \mathrm{~W} \mathrm{~K}^{-1} \mathrm{~m}^{-1}\right)$.

The electrical conductivity, $\sigma_{0}$, the thermal coefficient of resistance, $\alpha$, and the wire length, $l$, were considered constant during the minimization and their values are $59.6 \times$ $10^{6} \mathrm{~S} \mathrm{~m}, 3.93 \times 10^{-3}{ }^{\circ} \mathrm{C}^{-1}$ and $0.218 \mathrm{~m}$, respectively [17,5].

The minimization stopping criteria imposed a maximum of $10^{5}$ iterations or that for all sets of experimental the sum of square errors (between the measured values and those numerically) is lower than $10^{-10}$.

Fig. 5 shows the minimization results obtained after $10^{5}$ minimization iterations. The experimental results are also shown for comparison purposes.

The fitting error was quantified thought the calculation of the reduced $\chi^{2}$, the final optimization values are also gathered in Table 1.

The fitting reduced chi-square value is $1.7 \times 10^{-3}$, which corresponds to a probability higher than $99.99 \%$ for the hypothesis that the fit describes the deviations better than a random sample, confirming the goodness of the fitting to the proposed thermal model.

\section{Conclusion}

We have obtained an accurate estimation for the temperature of thin bonding wires, by using a FBG-based sensor and an adequate equivalent thermal model for the wire and the sensor. A comprehensive model that incorporates all the terms was developed and used to characterize variations of temperature as function of the conducted electrical current. From the estimated values we could predict the real temperature values in thin wires, based on the temperature measured, using a non-invasive sensor based on an FBG superimposed on an optical fiber. A good agreement was obtained between the simulated and the experimental values, suggesting a relevant technique for the prediction of temperature in thin wires. An ability to determine the maximum current value that could be injected in the system could be estimated and thus improve the performance of electronic devices.

The minimization stopping criteria imposed a maximum of $10^{5}$ iterations or that for all sets of experimental the sum of square errors (between the measured values and those numerically) is lower than $10^{-10}$. The fitting reduced chi-square corresponds to a probability higher than $99.99 \%$ for the hypothesis that the fit describes the deviations better than a random sample, confirming the goodness of the fitting to the proposed thermal model.

\section{Acknowledgment}

P.F.C. Antunes, H.F.T. Lima and A.M. Rocha acknowledge the financial support from Fundação para a Ciência e Tecn- ologia (FCT) through the Ph. D fellowships SFRH/BD/ 41077/2007, SFRH/BD/30295/2006 and SFRH/BD/41773/ 2007. This work was partially supported by the FEFOF Project (PTDC/EEA-TEL/72025/2006), financed by the European Union FEDER fund and by the Portuguese scientific Program.

\section{References}

[1] P.S. Andre, P. Antunes, et al., Simplified heat exchange model for semiconductor laser diodes thermal parameters extraction, Laser Physics Letters 2 (11) (2005) 525-528.

[2] P. Antunes, H. Lima, et al., Elastic constant measurement for standard and photosensitive single mode optical fibres, Microwave and Optical Technology Letters 50 (9) (2008) 2467-2469.

[3] P.F. da Costa Antunes, H.F.T. Lima, et al., Optical Fiber Accelerometer System for Structural Dynamic Monitoring, Sensors Journal IEEE 9 (11) (2009) 1347-1354.

[4] S. Dhokkar, P. Lagonotte et al., Experimental setup for the measurement of local temperature in electronic component during the steady and transient state, in: 2007 50th Midwest Symposium on Circuits and Systems, vols. 1-3, 2007, pp. 995-998.

[5] C.D.A. Inc., Copper.org. Retrieved January 2010, from <http:// www.copper.org/resources/properties/homepage.html>.

[6] D.A. Jackson, A.B.L. Ribeiro, et al., Simple multiplexing scheme for a fiber-optic grating sensor network, Optics Letters 18 (14) (1993) 1192-1194.

[7] Y. Jiang, Four-element FBG acceleration sensor array, Optics \& Lasers in Engineering 46 (9) (2008) 695-703.

[8] J. Jung, Y.W. Lee et al., Novel interrogation system for dynamic strain measurement based on fiber Bragg grating sensor using long period grating pair and EDF, in: Lasers and Electro-Optics Society 2000 Annual Meeting. Puerto Rico, vol. 2, 2000, pp. 679-680.

[9] A.D. Kersey, T.A. Berkoff, et al., Fiber-optic Bragg grating strain sensor with drift-compensated high-resolution interferometric wavelength-shift detection, Optics Letters 18 (1) (1993) 72-74.

[10] A.D. Kersey, T.A. Berkoff, et al., Multiplexed fiber Bragg grating strain-sensor system with a fiber Fabry - Perot wavelength filter, Optics Letters 18 (16) (1993) 1370.

[11] H.F. Lima, R. da Silva Vicente, et al., Structural Health Monitoring of the Church of Santa Casa da Misericórdia of Aveiro Using FBG Sensors, Sensors Journal IEEE 8 (7) (2008) 1236-1242.

[12] E. Loh, Physical Analysis of Data on Fused-Open Bond Wires, IEEE Transactions on Components Hybrids and Manufacturing Technology 6 (2) (1983) 209-217.

[13] A. Mertol, Estimation of Aluminum and Gold Bond Wire Fusing Current and Fusing Time, IEEE Transactions on Components Packaging and Manufacturing Technology Part B-Advanced Packaging 18 (1) (1995) 210-214.

[14] G.T. Nobauer, H. Moser, Analytical Approach to Temperature Evaluation in Bonding Wires and calculation of Allowable Current, IEEE transactions on advanced packaging 23 (3) (2000) $426-435$.

[15] A. Othonos, K. Kalli, Fiber Bragg Gratings, Fundamentals and Applications in Telecommunications and Sensing, Artech House, 1999.

[16] G. Paez, M.K. Scholl, Thermographic evaluation of Er-doped silica fiber as IR-to visible image converter. QIRT 2004, Bruxelles, Belgique, 2004.

[17] J.F. Shackelford, W. Alexander, CRC materials science and engineering handbook, Boca Raton, FL, CRC Press, 2001.

[18] M. Volanthen, H. Geiger, et al., Simultaneous monitoring of multiple fibre gratings with a single acousto-optic tunable filter, Electronics Letters 32 (13) (1996) 1228-1229.

[19] L. Zhang, R. Fallon et al., Large-Dynamic-Range and High Resolution From a Strain Sensing System Using Long-Period Grating Interrogating FBG Strain Sensor, ECOC'98. Spain, 1998, p. 609.

[20] D. Zhao, X. Shu, et al., Sensor interrogation technique using chirped fibre grating based Sagnac loop, Electronics Letters 38 (7) (2002) 312-313. 